\title{
Choices in language education: principles and policies
}

Norbert Pachler

Institute of Education, London

The extended editorial provides a general introduction to the individual contributions to this Special Issue on 'Choice in language education'. Together with the concluding piece by Lid King, it frames the various cases presented, and offers a discussion of the broader socio-political, cultural, economic and conceptual context within which they are located and against which they can be read. It examines issues of language choice with reference to recent policy initiatives at the level of the UK and the European Union and it discusses general principles concerning language choice. Finally, it introduces the various contributions to this Special Issue.

The context for and principles of linguistic choice in language education

Socio-political changes at macro and meso levels pose considerable challenges for (foreign) language education at the beginning of the $21^{\text {st }}$ century:

On the one hand, but only up to a point, the strong pressures of the new digital media, of globalisation and of a shrinking world make the need for proficiency in English as the lingua franca a sine qua non for many spheres of life. These developments can be seen to pose a real threat to linguistic diversity if diversity is understood as an interlinguistic rather than an intra-linguistic phenomenon, that is, if we don't take into account the increasing differentiation within English. Globalisation also brings into the communicational mainstream a proliferation of different variants and varieties of English, so-called Englishes, which develop dynamically in the contexts in which they occur.

Furthermore, it might be argued that 'English' in an older sense becomes less and less adequate as a descriptor for linguistic and sociolinguistic practices under that banner: the multiplication of varieties both spoken and written as an effect of globalisation and technologies makes the more nuanced view of 'language' in education necessary, one that takes into account the widening gap between socially available recourses (from popular culture, technology etc) vs the assumed necessary resources for achieving academically. These developments must have their effect on any notions of choice.

In his recent book English Next, David Graddol (2006) charts the rise of what he calls 'Global English' and he argues that, whilst modernity was characterised by nation states looking for nation-wide languages, post modernity is characterised by a decline in monolingualism. Citizens of the post modern world, in order to be socially and geographically mobile and in order to be able to make an active contribution to the societies in which they live, need to be fluent not only in standard national languages but also in one (or more) lingua franca, even if they do not aspire to physical mobility; this, among other things, is due to changes in business practices inherent in globalisation, such as the mobility of capital and consequent export of jobs. Traditional distinctions between 'owners' and 'users' of languages as well as of ethno-national identities being associated with speakers of a particular language are 
becoming increasingly blurred and distinctions between 'native' and 'non-native' speakers of a language are becoming increasingly understood in terms of differentials in functional proficiency in a language.

In addition to English, other strong contenders to the status of lingua franca are emerging, particularly in some regions of the world. Graddol, for example, asserts that Mandarin and Spanish have become sufficiently important to influence national policy priorities in countries like South Korea and Brazil respectively. His argument has a strong economic basis: he quotes statistics whereby production in English speaking countries currently accounts for around 30\% of the world Gross Domestic Product but is likely to account for less in the future. This leads Graddol to question the continued global predominance of English due to complex international economic, societal, technological and cultural changes all of which, in the foreword to his book, lead Neil Kinnock to conclude that there is no room for complacency in terms of the need to develop additional language capability.

On the other hand, in the context of the European Union, from where I write, the ambitions for enlargement on the grounds of economic competitiveness as well as of greater political and social integration - the EU now comprises 25 member states and heated discussions are being had about additional extension into Asia - has brought with it a strengthened commitment by Brussels to support linguistic diversity ideologically and financially given the growing strength of local and regional identities, which offers real opportunities in terms of linguistic choice.

In a final analysis, the question of choice in (foreign) language education is intimately linked to that of political social economic aims and is played out not only at the level of political entities such as national governments (the meso level) and supranational entities (the macro level) but, importantly, as the contribution by Lam in this Special Issue clearly shows, at the level of the individual. One fundamental question for policy makers is whether or not to consider foreign language competence as a basic skill in the same way as L1 literacy, numeracy and technological literacy are considered to be core skills in the UK. The spectrum of aims potentially underpinning foreign language education, on which this Special Issue mainly focuses, as opposed to mother tongue education, which is only touched upon, ranges from ambitions to reach near-native speaker proficiency in foreign language education and normative nativespeaker command as opposed to dialectal diversity in mother tongue education, on the one hand to the development of a heuristic linguistic competence or plurilingualism in John Trim's sense of the word, or the notion of 'the tuning of the ear' advanced by Eric Hawkins (1984). Trim (2005) defines plurilingualism as "the enlargement of an individual's overall communicative competence to include integrated competences in a number of languages”.

Suffice it to note here that the National Language Strategy for England (DfES, 2002) has nothing to say about the basic assumptions concerning language problematised above and very little about basic trajectories for language learning such as whether to foreground linguistic proficiency or intercultural competence. Languages are seen as a 'lifelong skill', 'to be used in business and for pleasure, to open up avenues of communication and exploration, and to promote, encourage and instil a broader cultural understanding” (p. 5). The vision espoused is as follows: 
we must provide an opportunity for early language learning to harness children's learning potential and enthusiasm; we must provide high quality teaching and learning opportunities to equip our young people with the skills they need to access opportunities in the world of travel and work; we must provide opportunities for lifelong language learning; we must recognise language skills as central to breaking down barriers both within this country and between our nation and others. (p. 4)

The commitment to an entitlement to foreign language learning for every pupil aged 7-11 including the development of their interest in other cultures, at the cost of making foreign language study at ages 14-16 optional, appears to be at best only partially informed by research evidence and one, therefore, needs to remain sceptical about the merits of this fundamental shift in policy. Research evidence from work on Second Language Acquisition and foreign learning is inconclusive about the arguments and assertions advanced in favour of this policy. McLaughlin (1992), for example, posits that the belief that children learn second languages quickly and easily and that the younger the child, the more skilled in acquiring a second language they become, are but myths.

At a systemic level, once a decision about including foreign languages as part of compulsory, i.e. state-funded, education has been reached, primary questions concerning language choice, in addition to those surrounding the status of foreign language skills in terms of key competences and the aims of foreign language education, are: which language(s), how many, for how long, at what level of intensity and to whom? Secondary questions concern issues such as didactics and pedagogy, that is, what modalities to use (e.g. face-to-face, at a distance or mixed-mode) and what approaches and/or methods to sponsor (e.g. mainly through exposure to and communication in the target language or through grammar-translation etc).

The history of foreign language policy in England in recent decades shows the difficulties of finding well thought-through answers to these questions. Ever since the introduction of the Modern Foreign Languages National Curriculum Orders in the early 1990s and the General Certificate of Secondary Education (GCSE) in the late 1980s foreign language educators and, of course, their pupils have been suffering from a number of unresolved tensions implicit in policy thinking and its articulation in curricular and assessment requirements. The emphasis on linguistic transactions of the GCSE and on summative standardised testing, rather than formative teacher assessment, added to the culture of league tables that has accompanied their introduction, has led to detrimental backwash effects such as a skills-based performance orientation rather than an emphasis on knowledge and understanding. Or, as another example, the near-native speaker competence espoused in the level descriptions of the attainment targets of the National Curriculum Orders are not only in stark contrast with the pragmatics, i.e. the effectiveness and fitness for purpose, and meta-pragmatics, the beliefs, views and perceptions, of language use in the real world but also to the minimal curriculum time allowances made. It can be seen, therefore, that choices in language education at the individual level are directly linked to the conditions set at the macro and meso levels.

In the UK, it can be argued, a shortage of foreign language teachers coupled with a considerable lack of motivation for foreign language learning, in particular amongst pupils aged 14-16 as a result, inter alia, of societal and political insularity as well as a 
certain disdain for linguistic 'otherness', has led to a knee-jerk reaction in policy terms, for instance, the breaking with a hard-fought-for policy of 'languages for all' at the first opportunity rather than to an examination of the underlying causes for the phenomena encountered such as systemic weaknesses with regard to the assessment regime and their impact on how curricular requirements are interpreted or the professional autonomy afforded to teachers.

The motivation behind a focus on choice in language education in this Special Issue is far removed from the present UK government's fetishisation of choice as the guarantor of excellence in its public services. It is ironic how the recent policy decision to make foreign languages optional in Key Stage 4 (aged 14-16), i.e. to give pupils the choice not to study a foreign language at all, has led to a steep decline in the take-up of languages. A sad facet of the current crisis, which has led the government to launch a review of its strategy by Lord Dearing, is the fact that the reasons for the choices made by pupils can be said to be mainly extrinsic and not intrinsic to foreign languages and foreign language learning. In particular, they can be seen to be attributable to culturally produced attitudes around the perceived difficulty of foreign language learning and the attendant negative impact in terms of progression through education to A-levels and the university (course) of ones choice. In a climate of commodification of education, where education is often seen in terms of an investment needing to yield financial returns, more occupationally-orientated subject, which are often also perceived as easier, or subjects, which might also be difficult but which are perceived as having higher status, are often preferred. Other extrinsic factors bearing on pupils' decisions would appear to be to do with contextual matters such as the narrow transactional orientation of foreign language curricula and pedagogies by government as well as unfavourable socio-cultural conditions, in particular the low status of foreign language proficiency in society.

By introducing a number of 'cases' from different parts of the world, this Special Issue concentrates on the tension between choices made at policy level in the field of language education and the way these are mediated through practice and affect teachers and learners locally.

The dangers of monolingualism and the virtues of plurilingualism and education for democratic citizenship

The most recent survey carried out by the National Centre for Languages (CILT et al, 2006), based on responses to a questionnaire sent to 2,000 secondary schools in the state and independent sectors (return rate 54\%), makes bleak reading with only $18 \%$ of maintained schools, of which about half are Specialist Schools, operate a 'languages for all' policy in Key Stage 4. The survey suggests that $29 \%$ of maintained schools have fewer than $25 \%$ of their pupils studying a language beyond the age of 14. And this despite the fact that it is not uncommon, certainly in the East End of London, to find schools where more than 70 languages are spoken!

The survey furthermore suggests the following trends in terms of the types of school least likely to have substantial numbers of pupils studying foreign languages:

- $58 \%$ of comprehensive schools, as opposed to $10 \%$ of grammar schools;

- $85 \%$ of the lowest-performing schools; 
- $\quad 74 \%$ of schools with high proportions of pupils eligible for free school meals;

- $74 \%$ of Specialist Business and Enterprise Colleges;

- $71 \%$ of Specialist Maths and Computing Colleges;

- $70 \%$ of schools in the North East (the region with the lowest take-up of languages) and

- $45 \%$ of schools in the East of England (the region with the best take-up of languages).

Therefore, a trend towards the study of foreign languages becoming an elitist subject is clearly discernible.

In higher education, the situation isn't much better. A recent report by Hilary Footitt (2005), commissioned by the DfES, suggests that there has been a marked national decline in the numbers of undergraduates taking languages. Between 1998-9 and 2001-02, at a time when overall student numbers were expanding, the number of UK domiciled students taking languages at English universities fell by 15\%. This, the report rightly notes, has clear implications for the supply of teachers and specialists in the future. The report also notes that there is an increasing concentration of undergraduate numbers in particular types of Higher Education Institutions with 46\% of the total national complement of undergraduate language students in 2001-02 being located in 14 Russell Group, i.e. 'elitist' research intensive, institutions. Footitt's research stresses that this decline has happened despite Schools of Languages having gone through considerable changes trying to adapt to changing circumstances and to maintain some provision.

In short, in a context of opposing meso-level developments discussed earlier, England appears to be heading towards monolingualism in its education provision. Clearly, this has considerable implications for the country including, but by no means first and foremost, in economic terms: the adage of the customer's language being the most important language is well known. Significantly, monolingualism fundamentally threatens European integration and can be seen as a major stumbling block to mutual understanding as well as to cultural diversity. This point is, of course, equally valid in terms of world peace. For those who see language and culture closely interrelated (cf. Byram et al's (1994) notion of language-and-culture), and I count myself amongst them, many cultural achievements are closely linked to specific languages and intellectual traditions. (see also de Cillia et al, 2001)

In his vision statement for foreign language education, John Trim (2004) cogently argues the dangers of monolingualism in terms of the sense of insularity it reinforces and how it militates against mobility and dependency on intermediaries in the understanding of others:

Monolingualism makes the success of communication dependent on the interlocutors' command of what is to them a foreign language. This is harmful in more ways than one. It means that one may not have access to the other person's ideas and feelings in proper depth, and it encourages native English speakers to feel a false sense of superiority, to talk too much and listen too little. They may even leave the impression of an arrogance, rooted in imperialist attitudes, that is only prepared to communicate on its own terms, under conditions which ensure its own superiority. Unequal communication arouses hidden resentments and leaves unspoken reservations unresolved. At 
worst, ignorance of the foreign reality exposes monolinguals to exploitation by the malevolent through misinformation, bringing an ugly element into international relations.

In other words, monolingualism is not a realistic choice for language policy in the $21^{\text {st }}$ century, despite the fact that recent foreign language policies for England can be seen to represent a distinctly retrograde step from the 1990s policy of 'languages for all' and go against public interest no matter how hard the government tries to put a positive spin on them.

McPake et al, in a paper soon to be published by the Language Learning Journal, for example, delineate the following benefits of linguistic diversity:

- improved international relations and trade;

- cultural enrichment;

- social inclusion;

- educational advantage and

- linguistic advantage.

Doubtless, there are others.

Choice of language, therefore, is predicated on linguistic diversity and the question arises which particular model of linguistic diversity to aspire to. Generally speaking there is the model of multilingualism and that of plurilingualism.

According to Wikipedia (http://en.wikipedia.org/wiki/Multilingualism accessed on 26-11-06), the term multilingualism can refer to phenomena regarding an individual speaker who uses two or more languages, a community of speakers where two or more languages are used, or between speakers of different languages. Multilingualism can either be defined as being native-like in two or more languages or as being less than native-like but still able to communicate in two or more languages.

In a paper about 'spaces of multilingualism', Blommaert et al (2005, p. 197) cogently argue that "multilingualism is not what individuals have and don't have, but what the environment, a structured determinations and interactional emergence, enables and disables." In other words, even highly competent multilingual speakers can become “communicatively incapacitated when they are 'out of place”” (p. 198). As a consequence, they posit, multilingualism often occurs as 'truncated competence', i.e. "linguistic competencies which are organised topically, on the basis of domains or specific activities" (p. 199) and it should not be understood as 'full competence in different languages' (p. 199) but this tends not to be recognised by language policy. The resultant question for language choice is: what specific bits of language do we want people to acquire in a multilingualism model?

Plurilingualism, according to the Council of Europe's Common European Framework of Reference for Languages (2001, p. 4),

emphasises the fact that as an individual person's experience of language in its cultural contexts expands, from the language of the home to that of society at large and then to the languages of other peoples (whether learnt at school or college, or by direct experience), he or she does not keep these languages and cultures in strictly separated mental compartments, but rather builds up a 
communicative competence to which all knowledge and experience of language contributes and in which languages interrelate and interact. In different situations, a person can call flexibly upon different parts of this competence to achieve effective communication with a particular interlocutor.

For Trim the essential difference between plurilingualism and multilingualism is "that languages are not seen as simply existing side by side, quite separate in the mind, but as interacting to form one integrated competence upon any part of which a user may draw to meet the demands of communication”. Or, to put it differently, the spectrum spans from purist notions of linguistic performance to an understanding of foreign language education fundamentally as an integral part of education for democratic citizenship, i.e. to develop in young people as part of their full-time education an ability to deal maturely with the notion of 'otherness' (see e.g. Jones, 1995) and to display an openness to other cultures and ways of being as well as a sense of social responsibility. Trim's notion of plurilingualism seems particularly attractive as it countervails an inherent central shortcoming of bi- and multilingualism, namely its lack of reciprocity, i.e. the pressure it puts on minority speakers to become bilingual whilst native speakers concentrate on learning a lingua franca (see Trim 2004).

Plurilingualism, therefore, the CEF rightly posits (2001, pp. 4-5), profoundly modifies the aim of language education:

It is no longer seen as simply to achieve 'mastery' of one or two, or even three languages, each taken in isolation, with the 'ideal native speaker' as the ultimate model. Instead, the aim is to develop a linguistic repertory, in which all linguistic abilities have a place. This implies, of course, that the languages offered in educational institutions should be diversified and students given the opportunity to develop a plurilingual competence.

Furthermore, once it is recognised that language learning is a lifelong task, the development of a young person's motivation, skill and confidence in facing new language experience out of school comes to be of central importance.

Other issues around choice, for example, relate to the role of the mother tongues of minority pupils in the classroom and school curriculum. McPake et al (forthcoming), drawing on 2001 Census data, suggest that the UK is entering a period of 'superdiversity', characterised by "an increased number of new, small and scattered, multiple-origin, transnationally connected, socio-economically differentiated and legally stratified immigrants who have arrived over the last decade” (Vertovec, 2006). In such a context, what provision can an education system make in terms of drawing on L1 knowledge and proficiency of learners? What choices does a nation state offer through compulsory education and, therefore, state-sponsored socialisation?

An important issue in terms of language provision and choice relates to the difficulty in predicting future need in relation to foreign language skills: it is next to impossible to foresee which language a young person will need at what level and for what purpose in their later life. Again, what are the implications for choice?

All of these developments have significant implications and pose considerable challenges for the education system concerning language provision, not least in terms the requirement to engage with need-driven demand. A detailed consideration of these 
issues goes well beyond the scope of this editorial, however. Suffice it to note that learner-centeredness, independent language learning and the use of new technologies will have to play a central role. Ciekanski's piece about learner autonomy addresses some of these issues. For a detailed discussion see also Allford and Pachler (forthcoming.)

A number of the pieces in this Special Issue engage with the implications of linguistic diversity in modern society: Jones’ paper on Asset Languages, for example, demonstrates the importance of a flexible assessment system to allow learners to seek recognition for different levels of proficiency across a range of languages. And, Balfour's discussion of the linguistic landscape in South Africa brings the challenges for policy makers of complex contexts into focus.

\section{A European policy perspective:}

Let me turn briefly to recent policy developments in Europe as an antidote to what might be deemed to be a rather unenlightened approach in the UK.

Under the banner of 'Education and Training 2010', the European Council, at its Lisbon summit in March 2000 agreed that the European Union must become 'the most competitive and dynamic knowledge-based economy in the world capable of sustainable economic growth with more and better jobs and greater social cohesion' (http://ec.europa.eu/education/policies/2010/et_2010_en.html). In order to achieve this, a strategic framework of co-operation in the fields of education and training based on shared objectives across teacher training, basic skills, the integration of Information and Communication Technologies, the efficiency of investments, language learning, lifelong guidance, the flexibility of the systems to make learning accessible to all, mobility, citizenship education etc. was agreed. In the field of language learning, the European Commission published an action plan in 2003 entitled 'Promoting Language Learning and Linguistic Diversity' which sets out the following concrete steps to promote linguistic diversity and language learning.

Under the heading of 'life-long language learning', the document features the following sub-headings:

- 'mother tongue plus two other languages': making an early start;

- language learning in secondary education and training: content and language integrated learning;

- language learning in HE (each university should implement a coherent language policy clarifying its role in promoting language learning and linguistic diversity, both amongst its learning community and in the wider locality; study abroad, preferably in a foreign language, for at least one term; all students gain an accepted language qualification as part of their degree course).

Under the heading 'Better language teaching', it deals with:

- the language friendly school: holistic approaches;

- the languages classroom: e-learning;

- language teacher training: adequate use of the target language, 'electronic literacy', membership of professional support networks ;

- supply of language teachers;

- training teachers of other subjects and 
- testing language skills.

And under 'Building a language-friendly environment', it covers:

- an inclusive approach to linguistic diversity;

- building language-friendly communities and

- improving supply and take-up of language learning.

Again, a detailed analysis and comparison of this action plan with language policy in the UK would go well beyond the scope of this introduction, but, as on previous occasions, for example on the issue of the integration of a European Dimension in education in the 1990s, the question begs asking how serious the UK government is about European Union policy in view of the actions promoted in its National Language Strategy (DfES, 2002).

Based on the issues raised in this editorial, the principle choice faced by the UK in terms of its foreign language policy would, therefore, seem to be a fundamental one about whether, at a time of increasing linguistic and cultural diversity of society, to be content with monolingualism or whether to aspire to the more enlightened position of multilingualism or plurilingualism.

In an educational climate characterised by a standards-based discourse and an obsession with examination results and league tables, Yiakoumetti's paper offers some useful data about the potentially positive contribution the use of native dialectal variety in formal education can provide for learning. Also, Payne's paper points to the beneficial role of pupils as conduits to linguistic communities outside school.

\section{The contributions to this Special Issue:}

As has been noted earlier, choices are being made at policy level for many different reasons and they are based on different kinds of rationales. This Special Issue focuses on three main areas: language being used as a means of unifying a country or group of countries where many different linguistic groups are present (e.g. China, the UK, Europe), because a view is prevalent that equality is associated with uniformity (e.g. South Africa, Greece) or because a new 'vision' for language learning and teaching is being promoted (e.g. the UK).

The issue is divided into two parts: Part 1 deals with policy choice and Part 2 with learners' and teachers' voices.

Three papers constitute Part 1: a UK paper on the Language Ladder, a paper on South Africa and one on the use of standard Greek in Cyprus primary schools in a bidialectal context, the latter acting as a transition to the second part since the study offers a positive response to the effects of the standardization policy on pupils' achievement in that part of the Greek-speaking world.

These choices are contrasted in Part 2 with the voices of students and teachers involved in the educational process in contemporary societies and at different levels of education. Two papers concern the way policies - as institutionally mediated affect the way learners chose which languages they will study in two contrasted contexts (London multilingual secondary schools and adults in China). The last paper 
on the professional issues associated with language advising for adult learners in France concerns pedagogical issues related to the implications of policy decisions regarding languages and more specifically the relation between teacher and learner.

The introductory comments on the individual papers that follow will deliberately contain themselves to providing a brief overview of each paper as Lid King, the National Director for Languages, reviews the various contributions from a UK policy maker's perspective in the concluding piece.

\section{PART 1: POLICY CHOICES}

\section{Assessment and the National Language Strategy \\ Neil Jones, UK}

The basic choice discussed in this paper concerns how we value knowledge of a language: as a measure of academic achievement, or as a useful skill within a framework for accrediting functional language proficiency. The paper argues that language assessment in the UK has focused on the academic at the expense of the useful, that this has been to the detriment of language teaching, and that it has served the majority of language learners badly.

The paper introduces Asset Languages, the assessment system currently being developed by the University of Cambridge Local Examinations Syndicate (UCLES) to meet one of the three overarching objectives of the National Languages Strategy (DfES, 2002).

\section{A new journey with old symbols: university language policies, language choice and the politics of transformation in South Africa \\ Robert Balfour, South Africa}

This paper deals with the growth and development of the language policy for the newly merged University of KwaZulu-Natal. It takes as its reference the battery of policy documentation guiding the use of languages as medium of instruction in education and the recently developed language policies of a number of Higher Education Institutions (HEIs). These policies, aimed as they are to transform the terrain of language education and media of instruction at HEIs, have as their basis guidelines for language choice at the level of the parent, learner, school or tertiary institution in relation to language rights (as defined by the South African constitution). Language choice is an issue and challenge for educational institutions globally and thus this paper makes reference to the growing recognition, development and promotion of multilingualism in tertiary institutions in the UK. For South Africa, given the complexity of 11 official languages, the paper suggests that policy development, particularly when it attempts to legislate for language choice, runs the risk of using old discourses and paradigms to arrive at the ideals of transformation. With reference to policy development at a number of HEIs the paper argues that these represent, with limitations, a challenge to the hegemony of English and Afrikaans as the two dominant languages of higher education. The paper suggests that there is a need for greater critical reflection when designing and implementing such policies. 


\section{Choice of classroom language in bidialectal communities: to include or to exclude the dialect?}

Androula Yiakoumetti, Cyprus

The issue of dialect and education, in particular the issue of which code to use as the medium of instruction, has generated much heated debate in bidialectal societies. This debate is reflected in the literature on language policy. This study presents empirical evidence with a view to inform on the potential benefits of bidialectal education. Specifically, it deals with the effects that mother tongue use in bidialectal education has on language attitudes and performance. As previous research has made clear that inhibiting students from using their native variety can stifle learning, it aims to encourage Cypriot students to harness their native variety when learning their nonnative educational variety. The study empirically assessed how explicit and conscious learning about language has a different influence on bidialectal students' linguistic performance compared with implicit learning. The results of the empirical study are set in the context of the issue of prescription in language education and the issue of language ideology. The study's broader ramifications derive from the results' relevance to all bidialectal communities in which non-native everyday language usage is confined to certain niches such as formal education. The findings also hold immediate practical potential as they indicate which sorts of learning material are most likely to facilitate the reduction of non-standard occurrences in the speech and writing of students.

\section{PART 2: Learners' and teachers' voices}

\section{Language choices in China}

Agnes Lam, Hong Kong

This paper explores the language choices made by policy makers and by individual learners in multilingual and multicultural China. It is an attempt to illustrate how language planning decisions made at the state level relate to choices made by individual learners as to what languages or dialects they wish to learn. It also discusses how such learning requires learners to resolve in some way the intercultural tension inherent in becoming bilingual or multilingual. The study of language learning in China offers immense possibilities for understanding the dynamics of linguistic choices because it is a multilingual and multidialectal country. Against a linguistically rich tapestry, the choices to be made by the state as well as individual learners are an everyday reality. The paper concludes that while the state makes conscious educational choices overtly or covertly, individual Chinese teachers or learners within the constraints circumscribed by language policy also have to meet the challenge of making choices for their own development, not only in terms of what language or variety they wish to learn and to what degree but also in terms of how to reconcile the intercultural tension between learning English and retaining their Chinese culture or in learning Standard Chinese and retaining their cultural identity as speakers of other Chinese dialects or speakers of minority languages.

\section{Foreign language planning: pupil choice and pupil voice} Mark Payne, UK 
This paper discusses pupil choice in relation to foreign language status planning. Borrowing from language planning theory, foreign language status planning is defined here as those aspects of language planning that reflect social, pedagogical and linguistic issues with a particular emphasis on foreign language choice in relation to L2 learning. The prime focus is foreign language planning (FLP) in the context of secondary schools situated within multilingual communities in England. The requirement of specialist language colleges (secondary schools with specialist language status) in particular to both diversify foreign language provision and to meet the linguistic needs of their communities is considered. The contribution that pupil voice can make in this crucial area is also discussed.

It is argued in this paper that pupils have a key role to play within essentially traditional 'top-down' foreign language policy-making in secondary schools. The discussion is supported by qualitative pupil data collected from GCSE and A-Level pupils across two schools and communities. Empirical evidence shows that pupils and the 'pupil voice' can make a valuable contribution in the area of foreign language status planning. Pupils act as a 'conduit' to their respective linguistic communities and, as such, can provide a valuable insight in linguistic terms into the complex and nuanced issues inherent in such communities. Pupil language choices reflect perceived community linguistic needs. Finally, pupils demonstrate the ability to engage with complex linguistic and pedagogical issues and, as such, can make a worthwhile contribution to adult-focused decision-making and language planning discourses.

\section{Fostering learner autonomy: power and reciprocity in the relationship between language learner and language learning adviser Maud Ciekanski, France}

Developments in life-long learning, autonomy and ICT have given fresh impetus to the discussion of learning without teaching. This paper concerns modifications to the relationship between learner and adviser which occur in self-directed schemes. Observation of advising sessions between learners and experienced advisers sharing the same interpretation of autonomous learning and what advising means suggest that the latter assume multiple pedagogical roles when assisting learners and that they switch between these roles frequently with the same learner. To understand the nature and the purpose of these variations in advising, the study focuses on the linguistic and instructional aspects which characterize the advising sessions.

\section{COMMENTARY FROM A UK POLICY MAKER}

Lid King, National Director for Languages

\section{RFERENCES:}

Allford, D. and Pachler, N. (forthcoming) Language, autonomy and the new learning environments. Oxford: Peter Lang Publishing

Blommaert, J., Collins, J. and Slembrouck, S. (2005) 'Spaces o multilingualism.’ In Language \& Communication 25, pp. 197-216 
Byram, M. et al. (1994) Teaching-and-learning language-and-culture. Celvedon: Multilingual Matters

CILT, ALL and ISMLA (2006) Language Trends 2006. Languages in Key Stage 4. Available at: http://www.cilt.org.uk/key/languagetrends/2006/trends2006_ks4.pdf

Council of Europe (2001) The Common European Framework of Reference for Languages: Learning, teaching, assessment. Cambridge: Cambridge University Press

de Cillia, R.; Krumm, H.-J. and Wodak, R. (2001) Vienna manifesto 'The cost of monolingualism.' Available at: http://www.oeaw.ac.at/shared/news/2001/manifesto_e.pdf

DfES (2002) Languages for all: languages for life. London. Available at: http://www.dfes.gov.uk/languagesstrategy/pdf/DfESLanguagesStrategy.pdf

European Commission (2003) Promoting language learning and linguistic diversity. An Action Plan 2004-06. Brussels. Available at: http://europa.eu.int/comm/education/doc/official/keydoc/actlang/act lang en.pdf

Footitt, H. (2005) The National Languages Strategy in Higher Education. London: DfES (Subject Centre for Languages, Linguistics and Area Studies/UCML) Available at: http://www.dfes.gov.uk/research/data/uploadfiles/RR625.pdf

Graddol, D. (2006) English Next. British Council. Available at: http://www.britishcouncil.org/files/documents/learning-research-english-next.pdf

Hawkins, E. (1984) Awareness of language: an introduction. Cambridge: CUP

Jones, B. (1995) Exploring otherness: An approach to cultural awareness. London: CILT

McLaughlin, B. (1992) Myths and misconceptions about second language learning: what every teacher needs to unlearn. Educational Practice Report 5, National Centre for Research on Cultural Diversity and Second Language Learning. Available at http://www.ncela.gwu.edu/pubs/symposia/reading/article6/mclaughlin93.html

McPake, J., Tinsley, T. and James, C. (forthcoming) 'Making provision for community languages: issues for teacher education in the UK.' In Language Learning Journal

Trim, J. (2004) 'A vision for the future. UK MFL capability and the learner.' Unpublished address to the NLS Research Seminar held at the British Academy, September 2004

Trim, J. (2005) 'The role of the Common European Framework of Reference for Languages in teacher education.’ Unpublished lecture. Graz, September 
Vertovec, S. (2006) 'The emergence of super-diversity in Britain. Working Paper No. 25. Centre for Migration, Policy and Society, University of Oxford. Available at: http://www.compas.ox.ac.uk/publications/wp-06-25.shtml 